\title{
3. DIREITO CONSTITUCIONAL E PANDEMIA: RESPONSABILIDADE PELA JUSTIÇA SOCIAL E NECESSIDADE(S) DE SAÚDE PÚBLICA
}

Luís Meneses do VALE

\section{Intro dução}

Depois da exposição aos valores respigados pela sondagem especificamente bioética da pandemia e após a consideração dos direitos humanos, em cujo discurso se cruzam hoje vultosas problematizaçóes axiológicas de índole política, jurídica e moral, cabe agora ${ }^{1}$ atentar na constitucionalidade responsável por assumi-los e reflecti-los - crítica, constitutiva e fundamental-regulativamente - no (e desde o) projecto normativo-político global por que as comunidades políticas historicamente se auto-transcendem, segundo a intencionalidade específica dessa indagação por um certo nomos - do, pelo e para o - comum,

Ora, como a presente investigaçáo questione directamente a valia e capacidade prestacional exibida e prometida pelo direito e a política na resposta ao desafio colocado pela actual pandemia e a forte probabilidade de similares emergências no futuro próximo, impóe-se asseverar, logo à cabeça, o lugar e papel fundamental das constituiçôes na nossa comum responsabilidade pela justiça - social, jurídica, da saúde pública e dos cuidados de saúde: tanto na qualidade de Grundnorm do ordenamento legalmente positivado, como na de projecto cultural de ordenação e convivência sócio-política.

1 Descansando largamente no tratamento dogmático de que a tutela jurídico-pública (constitucional e administrativa) da saúde será objecto no próximo capítulo, para ensaiar um volteio mais teórico, de lances forçosamente imprecisos (que deferem pormenores para uma possível versão mais extensa e pormenorizada, a trazer à luz noutra instância). 
Se bem se vê, uma aturada análise jurídica do regime de necessidade ditado pela pandemia arriscar-se-ia seriamente a desviar-nos do propósito precípuo da investigação desenvolvida: menos assestada à auto-reflexão e auto-regulação do direito e da constituição, perturbados por esta ou outra situação emergencial, do que à crítica reflexão das funçôes sociais pelas quais procuram prevenir, precatar e combater semelhantes vicissitudes. Com efeito, mesmo no plano menos substancial do ordenamento, a garantia secundária de auto-subsistência constitui apenas uma parte da resposta jurídica e constitucional reclamada pelas circunstâncias, cedendo, neste escorço, à função primária e ao seu significado material relativamente à sociedade. Nada que haja de embotar a relação com as normas secundárias, terciárias (ou até quaternárias), sobretudo se densificadas por uma intelecção fenomenológica do modo-de-ser do direito e da normatividade constitucional (enquanto princípio de 'estrutura-ação): v.g., quanto ao momento sociológico-material das fontes, à realidade jurídica no seio do sistema, à eficácia e efectividade de que depende a respectiva vigência, e, sobretudo, à especifica racionalidade e método da sua praxis de realização. Na verdade, também indirectamente - enquanto lei básica ou suprema, lei das leis e fonte politica das fontes - ela acaba interpelada na sobredita tarefa de fundamental e estruturante conformaçáo normativo-material da sociedade (com toda a sua pluralidade de interesses, poderes e valores, e as práticas, instituiçôes e subsistemas societais que engendram e sustentam).

Omitindo explicitaçóes certamente devidas, mas aqui incabíveis, vale dizer que a constitucionalidade se intenciona, nesta sede, como dimensão quase ecológica ou eco-sistémica da nossa habitação social no mundo, enquanto sentido de valor subjacente ao design, arquitectura e dinâmica das instituiçóes justas, na complexa mediação entre o bem e a correç̧ão ou rectidão, pelas quais, participativamente, procuramos e cultivamos, em contexto de pluralidade, as possibilidades do comum; ou seja, que por essa esquiva justiça visam a paz, buscam a auto-correcçáo estabilizadora da estrutura social básica ou ensejam co-mover-nos à pro-moção da socialidade democrática e normativa indispensável à integração social. Daí que, não obstante os escrúpulos protestados, cumpra apurar se, e em que medida, ela logrará eximir-se às impugnaçóes compreensivelmente lavradas contra a tentaçáo tecnológico-social, de inspiração biopolítica, cujas técnicas de governamentalidade e disciplinaridade, através da metanóia individual e do governo dos corpos, a situação 
de emergência, o estado de excepção e o direito de necessidade, longe de transtornarem ou surpreenderem, apenas intensificariam, afinal ${ }^{2}$.

Desta feita, nas páginas que se seguem (I) proceder-se-á, primeiro, do ethos para o nomos, e dialecticamente entre ambos, a propósito da responsabilidade e do recíproco condicionamento e efectivação entre justiça e saúde que a teleonomologia constitucional pretende sancionar positivamente; (II) confrontar-se-á, depois, essa constitucionalidade socialmente responsável pela justiça e pela saúde com os limites e limitaçóes impostos e revelados pela ananké pandémica e a fractura tragicamente dilemática entre salus populi e suprema lex que nos faz sofrer, iluminando, tenuemente, os quadros teórico e dogmático (internacional e nacional) pertinentes. A essa luz se ensaiará (III) uma sumária crónica da resposta portuguesa à crise, reconstituindo racional-narrativamente os acontecimentos padecidos, com menção dos seus protagonistas, principais capítulos, episódios cruciais e assuntos recorrentes. Para concluir (IV), muito modestamente, com algumas liçóes sobre o passado e o presente e, quiçá, algumas sugestóes para o futuro, animadas pela confiança constitucional e a síntese de responsabilidade e esperança (P. Häberle) que por ela nos propomos redimir (J. Balkin).

Ao percurso, assim prefigurado, deverá prepor-se um último conjunto de explicitaçóes quanto à situação de partida e às falsas evidências com que pode facilmente trair-nos. Desde logo, e no imediato seguimento do exposto, a muito cauta expectativa em relação ao rol de ensinamentos possivelmente recolhidos nasce, não só de metodológica prudência histórico-filosófica quanto à alardeada magistralidade do passado, como também de uma dúvida concreta relativamente à natureza e jaez da experiência proporcionada pelo difícil período que atravessamos; nomeadamente, no que toca ao valor de prova e provaçâo que se lhe tem assinado, à laia de pretenso momento de verdade e moralizante ou propedêutico (se não terapêutico) castigo e sacrifício. Afinal

2 V. Günther Frankenberg, Staatstechnik: Perspektiven auf Rechtsstaat und Ausnahmezustand, Berlin: SuhrkampVerlag, 2010. A propósito da actual pandemia, v. Ming-Sung Kuo, "From Institutional Sovereignty to Constitutional Mindset: Rethinking the Domestication of the State of Exception in the Age of Normalization", in Richard Albert/Yaniv Roznai (Eds.), Constitutionalism under Extreme Conditions: Law, Emergency, Exception, Springer, 2020, pp. 21-39; e Pedro A. Villarreal, "Public Health Emergencies and Constitutionalism Before COVID-19: Between the National and the International", Ibidem, pp. 217-238. 
de contas, não se revela ele, também (ou sobretudo...), atreito à manipulação e difusão de falsidades, a ilusórias imagéticas, aos engodos e distorçôes perceptivas e mesmo a perversas sublimaçóes segregadas pelo nosso inconsciente? Parece longe de seguro, em todo o caso, que se nos ofereça como inequívoco factor de nitidez, que não de adumbramento, em matéria de auto-representação e autoideação individual e colectiva enquanto seres aí, no mundo e entre os outros.

As ambiguidades prolongam-se, etimologicamente, na oscilação conceitual entre excepção, necessidade e emergência, mesmo que alijemos, da sua pesada carga histórica e jurídico-dogmática, os termos empregues: (i) o primeiro, a expôr as insuficiências da lógica referência à regra, admitindo o potencial libertador da fuga ou escape, em contraste com a conotação negativa da expunção ou extracção de um conjunto ${ }^{3}$; (ii) a categoria alética, traduzida pelo segundo, a minar as condições da liberdade empírica ou transcendental e do sollen deôntico sobre elas erguido, abre a ferida nunca totalmente suturada de todas as monísticas (ou quando menos dialécticas) normativizaçóes das necessidades sociais; (iii) o terceiro, a diluir-se no genérico fluir dos acontecimentos contingentes, assomados como indomesticáveis e-ventos, ou então, na emergencialidade da vida (desde a filogénese, à ontogénese e à noogénese) e dos padróes culturais evolucionariamente gerados pela complexificação social.

Por fim, entre a luz e a sombra, a regra e a excepção, o necessário e o devido, haveria de esclarecer-se, fosse outro o fôlego, como encarar a diferença especifica do tempo que agora nos calhou, relacionando analogicamente o velho com o novo, numa inevitável reflexão crítico-reconstrutiva do próprio tertium pressuponendo (F. J. Bronze) pela racionalização da humana temporalidade histórica, em que se inscrevem as constituiçóes, enquanto respostas colectivas - de, para, por e perante algo e alguém.

Repudiando o novismo fascinado, tanto como o relativismo de um nibil novum sub sole (que absorve toda a surpresa na indiferença), deverão equacionar-se seja (i) o património que o general intellect acumulou em matéria de pandemias, seja (ii) o pecúlio histórico e reflexivo do direito constitucional, relativamente às situaçôes de emergência, neces-

3 De que norma-lidade ou norma-tividade - e com que sentido (emancipação, exclusão ou a-bandono) - sairíamos, e para onde (de qual dentro e para que fora)? 
sidade ou excepção, sem com isso menoscabar o kairós que a actual crise proporciona para uma crítica profunda da sociedade e a invençâo/ descoberta de critérios para a sua transformação.

Quanto à primeira (concorrendo embora também para a substanciação da segunda), basta recordar a sucessão de crises que vimos enfrentando - desde a irrupçáo do novo terrorismo, após o 11 de Setembro, passando pela débacle económico-financeira, em 2007, até à multiplicação de catástrofes naturais (tufôes, incêndios, cheias) e ao cúmulo de antecedentes pandémicos (a SARS, Gripe Aviária, Ébola, Zika) - e a acuidade que, em consequência, confere à agenda da preparabilidade e resposta ${ }^{4}$. No que concerne à segunda, conviria - antes de tudo - náo desprezar as mudanças que fenómenos relativamente semelhantes provocaram ao longo dos tempos ${ }^{5}$, e a exortaçáo que nos lançam, enquanto promessas incumpridas, muitas aspiraçôes e anseios nascidos desses episódios catástróficos ou do lento e pervasivo acúmulo de injustiças que, em escandalosa prorrupção, subitamente revelam ou sintomatizam.

4 Note-se que a OMS dedicou o relatório mundial de 2007 à segurança sanitária e propôs-se devotar ao lema da preparaçáo e resposta o ano de 2019, no âmbito de um plano quinquenal iniciado em 2018 - v. WHO, The World Health Report 2007: Global Public Health Security in the 21st Century, WHO, Geneva, 2007o Relatório do Director Geral, Public health emergencies: preparedness and response, Annual report on the implementation of the International Health Regulations (2005): Progress in the implementation of the five-year global strategic plan to improve public health preparedness and response (2018-2023), WHO, 2019. Não obstante, cfr. as observaçóes tecidas em 2017 por Andrew LAKOFF, na análise essencialmente teórica que desenvolve no seu: Unprepared. Global Emergency in a Time of Emergency, University of California Press, 2017. Aí se perspectivam e delineiam, aliás, dois modelos distintos de resposta às emergências: um baseado no cálculo do risco e num imperativo de precaução e outro assente na ideia de preparabilidade ou preparação potencial (preparedness). Ademais das alusóes feitas na candidatura do projecto vertente, v., mormente para dilucidaçóes terminológicas ocorrentes, Bruce Jennings/John D. Arras/Drue H. Barrett/Barbara A. Ellis (Eds.), Emergency Ethics. Public Health Preparedness and Response, Oxford University Press, Oxford, 2016; Chloe Sellwood/Andy Wapling (Eds.), Health Emergency Preparedness and Response, Cabi, Wallingford, Boston, 2016; Rebecca Katz/ James Banaski (Eds.), Essentials of Public Health Preparedness and Emergency Management, 2nd Edition, Jones \& Bartlett, Wall Street, 2019.

5 V., por todos, Walter Scheidel, The Great Leveler: Violence and the History of Inequality from the Stone Age to the Twenty-First Century, Princeton University Press, Princeton, 2017; Jared Diamond, Collapse: How Societies Choose to Fail or Survive, Penguin Books, London, 2005. 


\section{Responsabilidade e Constitucionalidade: entre Ethos e Nomos}

\section{Responsabilidade}

Apesar de seminal no universo das nossas referências normativas, a responsabilidade retiniu tardiamente na reflexão filosófica e - mais ainda - nas suas peculiares terminações políticas e sociais. Por sobre isso, a centralidade que se the reconhece no mundo jurídico e no discurso moral, de onde foi exportada recentemente para aquelas esferas, ameaça toldar-lhe o sentido, eminentemente prospectivo e positivo, institucional e estrutural ${ }^{6}$, com que aí se manifesta. Efectivamente, a afirmação de

6 Além de Hans Jonas e Karl Otto-Apel - lídimos percursores desta viragem na (ou para a) responsabilidade (e entre nós trazidos ao regaço do direito constitucional nas exaustivas e exemplares reflexóes como sempre desenvolvidas pelo Senhor Doutor João Loureiro), tem-se em vista a responsabilidade estrutural (pela conexão social) de Iris Marion Young, a responsabilidade institucional positiva de Yasha Monk, ou até o esquema de responsabilizaçáo pelo dano, assente em deveres negativos, de Thomas Pogge - v. Iris Marion Young, Responsibility for Justice, Oxford University Press, Oxford, New York, 2011; Yasha Monk, The Age of Responsibility. Luck, Choice, and the Welfare State, Harvard University Press, Cambridge (Ma), London, 2017; Thomas Pogge, World Poverty and Human Rights: Cosmopolitan Responsibilities and Reforms, 2nd ed., i.a. Polity Press, Cambridge, 2008. Louvando-se do contributo de Young (posta em diálogo com Derek Parfit, Christopher Kutz, Judith Lichtemberg, Mary Gray, Melissa Lane, Barbara Fried), cf Vafa Ghazavi, "Ethics at a distance", in The Politics of Care. From Covid 19 to Black Lifes Matter, Review \& Verso Books: Boston, 2020; Kathryn Siknink, "Rights and responsibilities in the Coronavirus pandemic", Open Global Rights, 30 March 2020 (texto que se reivindica também, muito sugestivamente, da Verantwortungsethik de Max Weber). Não se ignoram as dificuldades colocadas por estas transfiguraçóes da responsabilidade, nem as diferenças que as separam da tradicional configuração da responsabilidade jurídica, sobretudo atenta a estrita delimitação quoad modum e quoad substantiam que a matriz intersubjectiva desta última assegura. Todavia, torna-se impossível explanar nesta sede os notáveis esforços de consolidação do potêncial detectado e já libertado pelo eidos-ousia deste Oberbegriff da razão prática - cf., na expectativa de desenvolvimentos ulteriores, em ocasiáo mais propícia - Kurt BAYERTZ/ Birgit Beck, "Soziale Verantwortung Zur Entwicklung des Begriffs im 19. und frühen 20. Jahrhundert". Preprints and Working Papers of the Centre for Advanced Study in Bioethics Münster, 81, Westfälische Wilhelms-Universitäts, Münster, 2015; explorando as inúmeras declinaçóes possíveis da responsabilidade, Ludger HeIdbrink/Claus LaNGBeHN/Janina LoH (Hrsg.), Handbuch Verantwortung, Springer, Wiesbaden, 2017; Jan Henrik Klement, Verantwortung. Funktion und Legitimation eines Begriffs im Öffentlichen Recht, Mohr Siebeck, Tübingen, 2006; Joseph Raz, From Normativity to Responsibility, Oxford University Press, Oxford, 2012. 
uma responsabilidade pela justiça social, em geral, e pela saúde, em particular - para o que agora nos interessa - remete à radical recompreensão do Mit-Sein humano e da objectiva solidariedade a que o convocam as interdependências naturais, técnicas e culturais da socialidade assim hibridamente pressuposta, pela qual se rompe com a exclusiva e redutora circunscrição da categoria, dos ideários que sustenta e veicula e das repercussôes práticas que consequentemente irradia, à medular (e inabdicável, note-se!) imputação moral, repousada, em última instância, sobre a razão e a liberdade do sujeito transcendental, subjacente ao eu empírico e fenomenal.

Tal responsabilidade... responsabiliza-nos também pela constitucionalidade capaz de a honrar e pelo direito susceptível de lhe fazer jus, actualizando os valores-tarefas e as convicçóes-fins que a animam nas instituiçôes de uma cultura-ambiente favorável ao ethos correspondente e à responsividade micro, meso e macro em que se exprime a sua permanente abertura à alteridade e à estranheza. Gera-se, assim, uma cadeia de responsabilidades ${ }^{7}$ por um conjunto de bens, enleados, fáctica e normativamente (ou ôntica e axiologicamente), na dinâmica prática da respectiva realização.

De feito, a justiça social (inclusive de ambição global) enquanto exigência de realização estruturalmente integrada da igualiberdade pessoal ao longo das várias esferas societais, engendradas em torno do acesso aos principais bens colectivos, correlaciona-se, duplamente, enquanto factor e efeito, com a justa provisão de cuidados de saúde e a promoção e protecção da saúde pública, nas quais encontra duas das suas densas dimensões constitutivas ou expressivas ${ }^{8}$. Não há justiça social sem

7 Neil Levy, "Taking Responsibility for Responsibility", in Public Health Ethics, Volume 12, Number 2, 2019, pp. 103-113; John Coggon, "Legal, Moral and Political Determinants within the Social Determinants of Health:. Approaching Transdisciplinary Challenges through Intradisciplinary Reflection", Public Health Ethics, Volume 13, Issue 1, 2020, pp. 41-47.

8 Karien Stronks/Brigit Toebes/Aart Hendriks/Umar Ikram/Sridhar VenKaTAPURAN, Social justice and human rights as a framework for addressing social determinants of health. Final report of the Task group on Equity, Equality and Human Rights. Review of social determinants of health and the health divide in the WHO European Region, WHO Copenhagen, 2016; Richard Wilkinson/Michael Marmoт (Eds.) Social Determinantes of Health: The Solid Facts, $2^{\text {nd }}$ edition, WHO, Copenhagen, 2003. Sudhir Anand/Fabienne Peter/Amartya Sen (Eds.), Public Health, Ethics, and Equity, OUP, Oxford, 2004; CSDH, Closing the gap in a generation: health equity through action on the social determinants of health (Final Report of the Commission on 
saúde, nem saúde sem cuidados de saúde e políticas de saúde pública justas, do mesmo passo que estas, e aquela, beneficiam da justiça social e suas exigências e repercussões nos demais sectores.

Recobra assim legitimidade, numa espiral de correlaçóes inter-influentes, a responsabilidade infra-estrutural pela criação, manutenção e incremento de práticas e instituiçôes de atenção e resposta - equivale asserir, capacitadas para uma permanente atentividade, atendimento e responsividade, tanto às imediatas solicitaçôes e necessidades das pessoas, como aos múltiplos planos de expectativas fácticas e normativas que acalentam, e pelos quais legitimamente se movem, em relação a quaisquer ocorrências pessoais, de magnitude colectiva e até internacionais ${ }^{9}$.

\section{A constitucionalidade}

$\mathrm{Na}$ acepção, simultaneamente mais lata e mais estrita, para que nos remetem os estudos constitucionais e a moralidade politica de uns, bem como a jurisprudência e direito politicos ou a cultura e software constitucional, propugnados por outros, surpreendemos aqui a constitucionalidade na tripla encruzilhada (i) entre o nacional e o internacional, (ii) a normalidade e a normatividade (iii) o direito, a política e as arenas sociais.

No primeiro caso, à guisa de uma interconstitucionalidade construída como aspiração de inter e transculturalidade, a partir de subjectividades, práticas, instituiçóes, sistemas, e intençôes trans-estaduais; no segundo, como resposta sócio cultural (de cultura/nomos político-social) ao problema clássico da integração e ao risco de Zerfall (adorniana), contra o fatalismo do oráculo böckenfordiano e em detrimento, repita-se, dos modelos normativo-formal de Kelsen, estadual ou ordenamental-material de Schmitt e científico-espiritual de Smend; finalmente, a título de meta-medial trans-estrutur-ação ou trans-institucionaliz-ação integradora do pluralismo e diferenciação societais, numa molecularidade escalar (do nível regional ou local ao global), em torno da cronotópica

Social Determinants of Health), World Health Organization, Geneva, 2008; Daniel S. Goldberg, Public Health Ethics and the Social Determinantes of Health, Springer, Cham, 2017;

9 Sobre a responsividade, v. Luís Meneses do VALE, "Responsividade nos sistemas públicos de saúde: o exemplo da OMS", in Estudos de Homenagem ao Professor Doutor Figueiredo Dias, Volume IV, Coimbra Editora, Coimbra, 2010, pp. 1049-1106. 
incorporação ou radicação carnal do homem e dos módulos estatutários (e correspectivos eco-sistemas) da sua igual liberdade de realização.

Enquanto, na primeira instância, atende à mundialização do fenómeno pandémico, e na segunda se abre às provocaçóes suscitadas pela disrupçáo do quotidiano e do seu quadro normativo ${ }^{10}$, na terceira, retomando as anteriores, esboça a específica integração normativo-constitucional e multinível, em contexto de diferenciação societal global, sobre-estruturando os sectores sociais, a partir de dentro, com base nos direitos e respectivas instituiçóes de suporte ${ }^{11}$. Até que ponto espera e responde, resiste e confronta, então, desde o seu núcleo central, os ingredientes da tragédia (Jack Balkin), é o que importará saber, a partir do caso da saúde.

\section{Responsabilidade constitucional pela justiça na saúde pública}

Tomando por boa a evidência aduzida quanto ao círculo virtuoso que a justiça e a saúde proporcionam, sempre que mutuamente reforçadas através de correctas e justas mediaçóes regulativas e sancionatórias, preconiza-se a correspondente responsabilidade constitucional (jurídica e política) pela respectiva garantia ${ }^{12}$.

10 Já que a normativização das necessidades sociais, associando o bem-estar colectivo a valores/bens reconhecidos, e a felicidade individual a uma ideia eudemónica, demulce a resistência contrafactual à emergência de situações ditas de necessidade, repondo - pela enésima vez - um dos grandes problemas da filosofia prática pós-kantiana e, bem assim da teoria e metodologia jurídicas e políticas contemporâneas. Dificuldade a que as vias procedimental ou conflitual (discursivas ou de inspiraçáo sistémico-funcionalmente autopoietica), por um lado, não alcançam vencer de modo totalmente convincente, e com que o jurisprudencialismo, por outro, custosamente se debate quando suspensa, no plano macro ou mesoscópico, de uma também político-social normatividade de teleológica modelação das acçôes e instituições complexas, - designadamente, através do sistema de atribuiçóes e competências de entidades públicas finalizadas à satisfação de interesses colectivos.

11 Chamando a atenção, com outra profundidade, alcance e entorno, para a trans- ou supra-estadualidade das questóes em apreço, e o consequente apelo à internormatividade, Joáo Loureiro, "Bens, Males e (E) (E)stados (In)constitucionais: Socialidade e Liberdade(s): Notas sobre uma Pandemia”, in Revista Estudos Institucionais, v. 6, n. 3, set./dez. 2020, pp. 787-832.

12 Sobre o direito da saúde pública, v. Lawrence Gostin (Ed.), Public Health Law and Ethics. A Reader, University of California Press, Berkeley, Los Angeles, London, 2002 e John Coggon/Keith Syrett/A.M. Viens, Public Health Law: Ethics, Governance and Regulation, Routledge, London and New York, 2017. 
Numa interpretação ampla dos blocos constitucionais e das redes transnacionais de que fazem parte os países lusófonos, avultam as responsabilidades internacionais defluentes dos sistemas universais e regionais, genéricos e sectoriais de direitos ${ }^{13}$, com destaque para as obrigações estatuídas no PIDESC ${ }^{14}$ e precisadas pela jurisprudência doutrinal do Comité dos Direitos Sociais, quer em matéria de aplicabilidade, eficácia, intensidade, ritmo e alcance, quer através da distinção material entre deveres de respeito, protecção e realização (facilitação, promoção e prestaçâo), ou mediante a especificação das inerentes garantias de sistemas de saúde disponiveis, acessiveis (geográfica, financeira, cognitiva e tempestivamente) e aceitáveis, quer ainda com relação à saúde pública $\mathrm{e}$ às determinantes sociais do bem-estar. Exigências que o Protocolo Facultativo tornou mais pregnantes, e os Altos Comissários e Relatores Especiais densificaram e determinaram com enorme coragem e frontalidade nos últimos anos.

A nível interno ${ }^{14}$, junta-se-lhes a adesão a um paradigma desenvolvimentista - precoce e precipitadamente desacreditado, como a história

13 V. Convenção Internacional sobre Eliminação de todas as Formas de Discriminação Racial (12º e 11.\%/1, Convenção sobre os Direitos da Criança (24. ${ }^{\circ}$ ), Convenção sobre os Direitos de Pessoas com Deficiência (25. $)$, Carta Social Europeia (11. e 13. ${ }^{\circ}$ ), Carta dos Direitos Fundamentais da UE (...), Convenção de Oviedo (art 3. ${ }^{\circ}$ ), Carta Africana dos Direitos do Homem e dos Povos (16.0); Carta Africana sobre o Bem Estar da Criança (14. ${ }^{\circ}$ ); Protocolo Adicional à Convenção Americana sobre Direitos Humanos em matéria de Direitos Econômicos, Sociais e Culturais (Protocolo de San Salvador), (art 10. ${ }^{\circ}$ ), entre outros...

14 V. art. 12. Cfr Luís Meneses do VAlE, "Sobre o sentido jurídico do acesso aos bens sociais fundamentais: a 'jurisprudência doutrinal' da ONU em matéria de saúde", e-cadernos CES, 15, 2012: 70-97; já no decurso e a respeito da pandemia, cf. Pedro A. Villarreal, "Can They Really do That? States' Obligations Under the International health regulations in Light of Covid 19" (Part I e II), in in Barrie SANDER/Jason Rudall (eds.), COVID-19 and International Law, Opinio Juris Symposium, March 30, 2020; Tim Fish Hodgson \& Ian Seiderman "COVID-19 Responses and State Obligations Concerning the Right to Health", Part I and II, Ibidem.

15 Descontados agora direitos correlacionados e os princípios fundamentais da constituição e do regime jussubjectivo (ou as tarefas gerais e as incumbências prioritárias do Estado na Economia), v. Constituição da República Portuguesa (art. 64. ${ }^{\circ}$ ), Constituição da República Brasileira (196. a $199 .^{\circ}$, além do art. 6.º); Constituiçáo da República de Angola (77. ${ }^{\circ}$, mas também 21. ${ }^{\circ}$ ); Constituição da República Moçambicana (89. ${ }^{\circ}$ e $1160^{\circ}$ ). Por su vez, segundo o Artigo $123 .^{\circ}$ da Lei Básica da Regiáo Administrativa Especial de Macau, o Governo Regional define, por si próprio, a politica respeitante à promoção dos serviços de medicina e saúde e ao desenvolvimento da medicina e farmacologia chinesas e ocidentais. As associaçóes sociais e os particulares podem prestar, nos termos da lei, serviços de medicina e saúde de qualquer tipo. Os Serviços de Saúde 
vem revelando ultimamente - que relaciona os direitos sociais com as políticas públicas ${ }^{16}$, nos moldes daquele constitucionalismo transformador comum, teorizado por A. Von Bogdandy, a propósito da América Latina. O que uns detractam como romantismo e idealismo aspiracional - assaz mal encarado no norte global (enquanto escusado bloqueio e complicação jurídicos, ingenuidade utopista ou pura compensação simbólica) mas partilhado com os países mediterrânicos - comparece nos princípios fundamentais e estruturantes, tarefas e incumbências do Estado, na garantia dos vários sectores de produção, na subordinação política da economia, na preocupação de interação e coesão social, e claro, na umbilical relação estabelecida entre os direitos sociais e as respectivas garantias institucionais de realização, mediante infra-estruturas democraticamente socializadoras como são os sistemas de saúde de tipo beveridgiano.

A distância entre norma e realidade, texto e acção, performance e impacto, percepção, apreciação e satisfação do público variam significativamente de Portugal para o Brasil, e deste para os países Africanos ${ }^{17}$, mas nem por isso se apequena o valor (intrínseco e consequencial) da opção constitucional por um modelo democrático-social (que não ape-

Públicos da RAE dependem da Secretaria dos Assuntos Sociais e Cultura e ocupam-se tanto da prestação de cuidados de saúde diferenciados e primários, bem como da execução das acçôes necessárias à prevenção da doença e à promoção da saúde (incluindo a vigilância epidemiológica, a educação para a saúde, a higiene alimentar, o controlo de vectores de higiene ambiental, a saúde ocupacional e a vigilância sanitária comunitária). Diga-se, por fim, que a actuaçáo das autoridade, durante a pandemia, se regeu, neste campo, pelas disposiçóes constantes da Lei n. ${ }^{\circ}$ 2/2004 (lei de prevenção, controlo e tratamento de doenças infeciosas), elaborada e aprovada na sequência da epidemia SARS, nos primeiros anos do actual milénio. Quanto à constituição da China, entre os Princípios Gerais estatui-se, no art. $21 .^{\circ}$, i.a., que o Estado, a fim de proteger a saúde das pessoas, deve desenvolver cuidados médicos e de saúde, assim como a medicina moderna e tradicional, encorajar e apoiar a gestão de várias infra-estruturas médicas e de saúde por organizaçôes económicas colectivas rurais, empresas públicas, instituiçóes públicas e organizações de vizinhança, e promover actividades de saúde pública. E no art. $45, \$ 1$, acrescenta-se que os cidadãos da república devem ter o direito a assistência material do Estado e da Sociedade quando forem idosos, estiverem doentes ou perderem a capacidade de trabalhar. $O$ Estado deve, pois, desenvolver a segurança social, a assistência social e os serviços médicos e de saúde necessários para os cidadãos gozarem deste direito.

16 Em Portugal e Angola nos vários números de um artigo, embora a afirmação de um direito resulte clara apenas no primeiro caso. Nos demais, em vários.

17 Sem falar no caso extremo de Macau. Tenha-se em vista, a título exemplificativo e aliás emblemático das duas culturas em causa, o contraste entre a escassa exploração da via judiciária em Angola e a judicialização acentuada no Brasil. 
nas assistencialista ou previdencial) de igualização (de todos para todos), alinhado ou sintonizado, de resto - seja quanto aos cuidados de saúde (graças à a universalidade, à generalidade ou compreensividade, e ao financiamento solidário), seja em relação a esses e outros factores determinantes da saúde colectiva, através do bem-estar - com os objectivos de desenvolvimento do milénio, a revolução ecológica ou ambiental-social no tocante aos determinantes de saúde e os melhores parâmetros, recomendaçóes e práticas internacionais nascidos das agendas da universalização, dos novos serviços públicos e comuns, dos sistemas integrados, da saúde global, das politicas orientadas para igualdade, etc.

Em suma, a preparação e responsividade às emergências de saúde avultarão numa sociedade: (i) solidariamente responsável, igualitária e coesa, onde a paz social e as possibilidades de realização são obras $d a$ justiça (que sedimenta a confiança interpessoal e institucional, contribuindo para a resiliência individual e colectiva); (ii) com políticas de saúde pública transversais aos vários sectores sociais e um sistema de saúde público justo, por legítimo e eficaz; (iii) dotada de capacidade para actuar de maneira integrada, com o respaldo dos cidadãos, combinando as políticas públicas globais com as sectoriais, reflectindo a saúde em todas elas e conjugando os vários planos de resposta do sistema de cuidados.

\section{Sob o Signo da Ananké: necessidade(s) de saúde}

\section{Aspectos geraiis ${ }^{17}$}

Quem se náo resigne ao escapismo formalista de um normativismo ideal e refuse capitular à soberania pré-jurídica de um poder mais ou

18 Como locus classicus sobre o tema, no século XX, v. obviamente, as obras de Carl Schmitt, sobretudo da década de 20, com realce, logo no início do decénio, para Die Diktatur. Von den Anfängen des modernen Souveränitätsgedankens bis zum proletarischen Klassenkampf, 1921 e Idem, Politische Theologie. Vier Kapitel zur Lehre von der Souveränität, 1922. Um resumo de fácil compreensão colhe-se em Elliot BuLMER, Emergency Powers, International IDEA Constitution-Building Primer 18, IDEA, Stockholm, 2018. Em termos eminentemente sociológicos, cf. Matthias LemKe, "What does state of exception mean? A definitional and analytical approach", Zeitschrift für Politikwissenschaft, 28, 2018, pp. 373-383; Idem (Hrsg.), Ausnahmezustand. Theoriegeschichte - Anwendungen - Perspektiven, Springer, Wiesbaden, 2017. Como testemunho muito próximo da heterogeneidade dos contributos disponíveis, v. as recentes 
menos teologizado, ou render-se à normativização de uma facticidade puramente contingente - trazendo antes, para o interior da normatividade, culturalmente inteligida e vivida, a tensão constitutiva entre axiológico-normativas exigências de ideal validade e prático-materiais instanciaçóes performativas da sua eficácia ou efectividade - depara, a propósito do instituto do direito ou estado de necessidade, emergência ou excepção, com uma verdadeira situação-limite, suspensa na ponte radbruchiana entre ser e valer, rasurada nas entrelinhas dos Schranken e Grenzen do direito e problematizadora dessas complexas dobras do existir, conhecer e avaliar humano que racionalmente gostaríamos de assegurar medial-dialecticamente produtivas e superiormente sintetizantes. Como se anunciou, o problema cresce em melindre se a jurisprudencialista superaçáo possível da dificuldade (mediante um juízo decisório culminante dessa espiral de correspondências, mutuamente afinadas, entre o sistema e a controvérsia jurídica, a problematicidade intencional da norma e a problemática do caso ${ }^{19}$ ) cede o passo a uma crítico-reflexivamente reconstitutiva relaçáo de amplo espectro entre normatividade e realidade social - como sucede no domínio, segundo a perspectiva e de acordo com a consciência intencional a que se abre o fenómeno da constitucionalidade.

A figura remonta aos primórdios da reflexão jurídico-política, designadamente no contexto da república romana (onde o ditador, nomeado pelas magistraturas superiores, era temporariamente investido dos poderes e símbolos de Imperium), tendo sido repensada por $\mathrm{Ma}-$ quiavel na transição para idade moderna, ou por Locke (teorizando os poderes de prerrogativa) e depois Rousseau e Harrington, já nos alvores da contemporaneidade, para explodir no dramatismo dos debates proporcionados pelo caldo cultural, político, económico e social em que se viu mergulhada a Republica alemã de Weimar. À conta sobretudo de Giorgio Agamben, foi reinventada pela filosofia continental de fins do

colectâneas: Gary GarstLE \& Joel IsAAC (Eds.), States of Exception in American History, University of Chicago Press, Chicago, 2020; Cosmin Cercel, Gian Giacomo Fusco, Simon Lavis (Eds.), States of Exception: Law, History, Theory, London: Routledge, 2020; Richard Albert/Yaniv Roznai (Eds.), Constitutionalism under Extreme Conditions: Law, Emergency, Exception, Springer, 2020.

19 Aqui, a negociação de facto e direito resolve-se por metodológica concentração progressiva no programa normativo e no âmbito material da norma (Müller), ou no encontro do pré-compreensivo juizo de um caso com as hipóteses normativas legalmente previstas (Esser) ou até das normas hipoteticamente construidas para o resolver com as disposiçóes efectivamente positivadas (Kriele). 
século XX e início dos XXI, sob inspiração da arqueologia foucaultiana e da teoria da violência de Walter Benjamin ${ }^{20}$, ao passo que a teoria constitucional norte-americana ${ }^{21}$ o revisitaria com afinco, no rescaldo dos ataques do 11 de Setembro e do novo paradigma internacional neobélico e internamente securitário, que veio a desencadear na América - e, progressivamente, um pouco por todo o mundo.

Posteriormente, a crise económica e financeira, pretextando a invocação de apósitos estados de emergência, gerou mais uma vaga de reconsideraçôes, que lhe alargaram e distenderam as fronteiras e o potencial significativo para os domínios da luta contra a normalização necessitante das formas de opressão e domínio patriarcal, neocolonial e económico-social, de alcance supra-estadual ${ }^{22}$.

\section{O quadro jurídico}

\subsection{TEORIA}

As situaçôes constitucionalmente relevantes de anormalidade prestam-se a variadas possibilidades de análise, autorizando a organização

20 Giorgio Agamben, Stato di eccezioni, Homo sacer, II, I, Bollati Boringhieri, Torino, 2003. V. igualmente a monumental edição completa da série dedicada ao homo sacer: Homo sacer (1995-2015). Ediz. Integrale, Quodlibet, Macerata, 2018; assaz menos convincentes se afiguram alguns dos últimos discreteios do autor, em especial o polémico conjunto de meditaçốes que foi produzindo no site desta sua editora e entretanto compilado em Idem, A che punto siamo? L'epidemia come politica, Quodlibet, Macerata, 2020.

21 Cf. Bruce Ackerman, "The Emergency Constitution”, The Yale Law Journal, Vol. 113, 2004, pp. 1029-1091 e a discussão gerada pelas posiçóes do professor de Yale: v.g., David Cole, The Priority of Morality. The Emergency Constitutions Blind Spot", The Yale Law Journal, 113, 2004, 1753 e ss; Kim Lane Scheppele, "Law in a Time of Emergency: States of Exception and the Temptations of 9/11", Journal of Constitutional Law, Vol. 6, 5, May, 2004, pp. 1001-1083; Laurence H. Tribe and Patrick O. Gudridge, "The Anti-Emergency Constitution”, Yale Law Journal, 113, 2004, pp. 1801 e ss; Martha Minow, "The Constitution as Black Box During National Emergencies: Comment on Bruce Ackerman's Before the Next Attack: Preserving Civil Liberties in an Age of Terrorism", Fordham Law Review, 75, pp. 593 (2006).

22 V., por exemplo, Lorenzo Cotula, "The state of exception and the law of the global economy: a conceptual and empirico-legal inquiry", Transnational Legal Theory, 8:4, 2017, pp. 424-454; José Atiles-Osoria, and D. Whyte, "State of Exception, Law and Economy: A socio-legal approach to the economy of exception in an era of crisis", in Oñati Socio-legal Series, 8 (6), 2018, pp. 808-818. Foram-se-lhe juntando, no interim, os desastres ambientais - mais ou menos localizados (como sucedeu com o furacão Katrina) e as epidemias surgidas sobretudo a oriente ou em África. 
de tipologias muito heterogéneas, conforme os critérios ou ao longo dos eixos de sistematização utilizados: tempos, sujeitos, poderes, medidas, efeitos, objectos, etc. Assim se admitem modelos e modalidades ditos monistas e dualistas, de autorização ou ratificação ${ }^{23}$, envolvendo poderes implícitos ${ }^{24}$ ou cláusulas expressas de habilitação ${ }^{25}$, estritamente vinculados, discricionários, de liberdade ou irresponsabilidade, ordinários ou extra-ordinários, jurídicos ou extra-jurídicos, constitucionais ou legislativos, politicos ou administrativos, suspensivos ou restritivos de direitos, etc. Cerzindo algumas das taxonomias mais conseguidas, talvez seja lícito estacionar na destrinça entre modelos de previsão e acomodação jurídica de irrelevância continuista e de reacção extra-jurídica ${ }^{26}$.

\subsection{DOGMÁTICA}

a) Nacional: face ao tratamento de que é objecto no próximo capítulo deste livro branco, dispensam-se, por ora, lucubraçóes minimamente detidas sobre o ponto vertente, satisfazendo-se a composiçáo discursiva com o ressalto de que o corpus constitucional luso permite distinguir entre estado de necessidade externo (de guerra ou emergência militar) e interno. Ladeada, dentro da modalidade em apreço, pelas situaçôes de grave ameaça ou perturbação da ordem constitucional democrática, a ocorrência de pandemias, a par de outras catástrofes naturais, desastres ou acidentes graves, deverá corresponder, salvo melhor aviso, aos problemas intencionados normativamente com a referência a

23 Pense-se nos britânicos Bills de indemnidade, por exemplo.

24 Como, em boa medida, sucede nos EUA.

25 Tenha-se em vista o tristemente célebre $480^{\circ}$ da Constituição alemã de Weimar e o $16 .^{\circ}$ da Constituição Francesa de 58.

26 Oren Gross/Fionnuala Ní Aolaín, Law in Times of Crisis. Emergency Powers in Theory and Practice, CUP, Cambridge, 2006; David Dyzenhaus, The Constitution of Law. Legality in Time of Emergency, Cambridge University Press, Cambridge, New York et al, 2006; John Ferejohn/Pasquale Pasquino, "The law of the exception: A typology of emergency powers", International Journal of Constitutional Law, Volume 2, Issue 2, April 2004, pp. 210-239; baseando-se precisamente nestes autores, v. entre nós, Miguel Nogueira de Brito, "Modelos de Emergência no Direito Constitucional", e-Pública, Volume 7, N. o 1, Abril, 2020, pp. 6-26; cfr. ainda Jorge Bacelar GouveiA, O Estado de Excepção no Direito Constitucional: Entre a Eficiência e a Normatividade das Estruturas de Defesa Extraordinária da Constituição, vol. II, Almedina, Coimbra, 1998; Idem, Estado de Exceção no Direito Constitucional: Uma Perspetiva do Constitucionalismo Democrático - Teoria Geral e Direito Português, Almedina, Coimbra, 2020. 
calamidades públicas ${ }^{27}$. Verificados os respectivos pressupostos materiais, a constituição prevê a possibilidade de instituir um regime ou disciplina jurídicos de necessidade, essencialmente consistente numa suspensão colectiva de direitos que o presidente pode declarar - optando pelo estado de sítio ou de emergência, consoante a gravidade dos casos (e apesar das ténues linhas que os separam) -, mediante decreto apresentado à AR, depois de ouvido o governo, e sujeito à referenda governamental se, e quando, autorizado (ou confirmado) por aquela ${ }^{28}$. Além destes limites formais, procedimentais e orgânicos, de um ponto de vista material, (i) excluem-se do alcance potencial de suspensão alguns direitos e princípios constitucionais ${ }^{29}$, (ii) requer-se a especificação dos direitos afectados, (iii) define-se uma limitação temporal para os seus efeitos, e (iv) impóe-se especial cautela na observância dos princípios da proibição do excesso, bem como, naturalmente, da igualdade e da não discriminação. $\mathrm{O}$ regime principial continua a actuar como parâmetro da declaração e das medidas adoptadas na sua execução, garantindo a possibilidade de sindicância jurisdicional, para lá do controlo político parlamentar.

b) Internacional: merece ainda a pena realçar, conquanto liminarmente, a guarida que à derrogaçáo de direitos prodigalizam o PIDCP (art.04), apoiado pela Declaração de Siracusa e o Comentário Geral 29, bem como a Regulamento sanitário internacional, maxime no seu artigo 43. Largamente ignorado durante a gestão estatal e internacional da pandemia, este complexo normativo motivou mesmo uma exortação à observância por parte de Lawrence Gostin e outros especialistas, ainda nos idos de Fevereiro de $2020^{30}$. Com um fito de elucidaçáo colimado sem dúvida a uma maior divulgação, impregnação e inculcação

27 J.J. Gomes Canotilho, Direito Constitucional e Teoria da Constituição, 7.a edição, Almedina, Coimbra, pp. 1083 e ss

${ }^{28}$ Além do art. $19 .^{\circ}$, v. $134 .$, n. ${ }^{\circ} 1$, al. d); $138 .^{\circ}, 140 .^{\circ}$, n.o $1 ; 161 .^{\circ}$, alínea l), e 197. ${ }^{\circ}$, n. ${ }^{\circ} 1$, alínea f), da CRP.

29 De harmonia com o que se acautela também no art. 4..$^{\circ}$ do PIDCP, no $27 .^{\circ}$ da Convenção Americana dos direitos Humanos, ou no artigo $15 .^{\circ}$ da CEDH.

30 "Do not violate the International Health Regulations during the COVID-19 outbreak", The Lancet, 20 February, 2020 
na consciência colectiva e à modelação da agência dos entes públicos responsáveis, assim como das populações, alcançou-se e firmou-se, há não muito, o Consenso de Stellenboch ${ }^{31}$ sobre as respostas jurídicas nacionais aos riscos de saúde pública, peça cujo conteúdo não consente em deslindar-se neste curto espaço, mas que convida a um estudo dos nexos jurídicos com que, de futuro, deve enredar as responsabilidades estaduais em matéria de saúde em geral, e de saúde pública em particular, com outras exigências, de solidariedade global, comércio internacional e tutela de direitos, em parte condicionantes, senão constitutivas, das faculdades/capabilidades reais de bem-estar e realizaçáo pessoal essenciais ao suporte mútuo da saúde individual e colectiva.

\section{A Narrativa Nacional ${ }^{32}$ : do Pathos ao Logos}

Se a história só recorda sismograficamente os acidentes, esquecendo, entre os cumes agrestes da mudança, os vales planos de morna felicidade, não deve surpreender-nos o fascínio e atracção dos seus cultores pelos fenómenos epidémicos. A propensão metafórica e a prestabilidade alegórica não hão de pesar menos nesse cômputo, ao qual se anexa ainda a forma dramatúrgica que tendem a assumir (Charles Rosenberg)

31 O texto pode ser consultado na International Organizations Law Review, 2020, $1-68$.

32 Para uma reconstituição muito semelhante, v. Teresa Violante \& Rui LanCEIro, "The Response to the COVID-19 pandemic in Portugal: A success story gone wrong”, Verfassungsblog, 04 March 2021; Idem, "Coping with Covid-19 in Portugal: From Constitutional Normality to the State of Emergency", Verfassungsblog, 12 April 2020; Pedro Lomba, "The Constitutionalized State of Emergency. The Case of Portugal", Verfassungsblog, 15 April, 2020; Idem, "Constituição, estado de emergência e Administração sanitária: alguns problemas”, in e-Pública, Vol. 7, n. ${ }^{\circ}$ 1, Abril 2020, pp. 27-43; José Melo Alexandrino, "Devia o direito à liberdade ser suspenso? Resposta a Jorge Reis Novais", Observatório Almedina, 7 de Abril de 2020 (também em Revista do Ministério Público, Número Especial COVID-19: 2020, pp. 79-92); Jorge Bacelar Gouveia, "O estado de excepção no Direito Constitucional: uma introdução", Observatório Almedina, 26 de Março de 2020; Idem, "Portugal e a COVID-19: Balanço e Perspetivas de uma Ordem Jurídica da Crise", in Revista do Ministério Público, número especial COVID-19, ano 41, junho 2020; Catarina Santos Botelho, "Emergência preventiva, reactiva, cirúrgica, ...reforçada", Observatório Almedina, 25 de Janeiro de 2021. 
e a coreografia social que exibem à medida que se desenrolam no tempo e no espaço ${ }^{33}$.

Nos países lusófonos, a história conta-se a várias velocidades e ritmos, impossíveis de rastrear aturadamente, pelo que se acompanha apenas (e muito de alto), os meandros da novela portuguesa. Nela se divisam dois episódios de confinamento, iniciados em Março de 2020 e Janeiro de 2021, entremeados por um período de desconfinamento, a partir de Maio mas inflectido em Setembro; inclui três estados de emergência decretados em Março e Novembro (de 2020) e em Janeiro (de 2021), para conhecerem depois sucessivas renovaçôes; e escande-se, como num Leitmotiv, por uma duradoura e raro aliviada gestáo administrativa da calamidade, ao longo de quase todo este período. No elenco figuram actores institucionais de primeira monta, como o PR, a AR, o Governo, as Regiōes Autónomas, as Câmaras Municipais, a Administração da Saúde, os Tribunais e a Provedora, mas também os cidadãos e muitas das suas associaçóes cívicas e profissionais de representação (ordens, sindicatos, ligas, confederaçóes patronais, etc.), além dos meios de comunicaçáo social e das redes sociais - tornados postigos para o mundo de uma pletora de especialistas (promovidos da rectaguarda à antena) e de movimentos sociais mais ou menos inorgânicos. Entre muitos outros temas e, sobremodo, no meio de uma cópia imensa de pormenores náo despiciendos, três grandes questóes jurídicas mereceriam talvez um olhar mais demorado: a oportunidade e conteúdo da declaraçấo de estado de emergência e respectiva execução pelo governo; a administração em estado de calamidade; a realizaçáo de eleiçóes durante a pandemia - todas elas entretanto conducentes a propostas de iure condendo e lege ferenda, relativamente à constituiçáo e à legislaçáo vigente.

No essencial, os feitos podem narrar-se assim: face ao cenário internacional e apesar da ausência de casos em território português, a 2 de Março, o Governo começou a adoptar medidas restritivas, acobertado pela lei de protecçáo civil, pela lei de bases da saúde, e pela lei de vigilância sanitária. Uma forte pressão social, sobretudo por parte de profissionais de saúde, levou o PR a declarar o primevo estado de emergência, ainda que ao executivo fosse em princípio possível restringir os direitos afectados, no âmbito da reserva imanente de ponderação a que,

33 Jeremy A. Greene \& Dóra Vargha, "How Epidemics End”, June 30, 2020, in Thinking in a Pandemic: The Crisis of Science and Policy in the Age of COVID-19, op. cit. 
na formulação de Reis Novais, se encontram sujeitos ${ }^{34}$. Acresce que a declaração do Presidente náo suspendeu o direito à liberdade pessoal, precipuamente atingida pelo núcleo duro da intervenção governamental (e principal argumento para o recurso à sua suspensão, salvo erro), além de operar uma delegação de poderes de delimitação dos direitos suspensos cuja constitucionalidade náo se furta a dúvidas. Dificilmente se poderia dizer, em todo o caso, que as medidas do Governo se saldaram em mera execução do decreto presidencial, cabendo-lhes um papel afinal constitutivo, em termos materiais, na restrição dos direitos, razão por que deveriam ter revestido a forma legal, e não apenas regulamentar, como avonde veio a suceder. De todo o modo, após duas renovaçóes, sem alteraçóes significativas quanto a estes pontos problemáticos, o estado de emergência expirou a 2 de Maio, dando lugar a um estado administrativo de calamidade (por sua vez renovado até 28 de Junho), balizado pela legislação já citada, e sempre confiante na consciência cívica dos cidadáos, à medida que as restriçóes iam sendo gradualmente levantadas. Todavia, o sol de verão pouco durou, pois, em Setembro, os níveis de infecção voltaram a subir, ao mesmo tempo que novas estratégias, relacionadas com a vinculatividade do uso de máscaras e a equação de um sistema electrónico de rastreamento dos contactos humanos entraram na agenda; a primeira definitivamente, a segunda, titubeantemente, até se gorar por completo. $\mathrm{O}$ agravamento da situação ditou nova declaração de estado de emergência a 6 de Novembro, e o implemento de constrições mais severas durante o mês de Dezembro (recolhimento nocturno à semana, e desde as 13 horas, ao fim-de-semana). $\mathrm{O}$ fracasso da contenção ensejada durante o período festivo (quiçá devido à complexidade regulática das medidas), combinado com o surgimento precoce de novas estirpes no país, redundaram no período mais negro da pan-

34 Jorge Reis NovaIs, "Estado de Emergência - Quatro notas jurídico-constitucionais sobre o Decreto Presidencial", Observatório Almedina, 19 de Março de 2020; Idem, "Direitos Fundamentais e inconstitucionalidade em situaçáo de crise - a propósito da epidemia COVID 19", in e-Pública, Vol. 7., N. 1 Abril, 2020, pp. 78-117; Pedro Costa GonçALVEs, "Abdicação parlamentar na emergência e continuação da abdicação na calamidade", Observatório Almedina, 21 de Maio de 2020. Via semelhante recomendam vários autores, como Martin Scheinin, no plano internacional. Na Alemanha lamentou-se, inversamente, a ausência de medidas constitucionais expressamente invocáveis. Para uma panorâmica comparada da resposta, v. as ligaçóes contidas em Joelle Grogan, "Power and the COVID-19 Pandemic - Introduction \& List of Country Reports", VerfassungsBlog, 2021/2/22. 
demia, em Janeiro, induzindo novo confinamento, a meio do mês, ante os números alarmantes de óbitos e infecçóes, o congestionamento dos hospitais e a iminente ruptura do sistema. Não tendo sido precavida a realização, em maior segurança, das eleiçóes presidenciais, nada obstou, porém, a que o acto tivesse decorrido na data prevista. Pelo contrário. E se náo convencem completamente os argumentos expendidos em prol de um possível adiamento (sem prejuízo de os prazos constitucionais admitirem uma relativa dilacção), mais os sobrepuja a preocupação em manter uma salutar regularidade democrática. Da experiência se retira, todavia, a necessidade de ponderar tranquilamente uma reforma do sistema, ainda que sem embarcar numa ocasional e dermicamente reactiva alternativa electrónica, carente de estudos e debate; e isto porque veio à tona a impreparação logística da administração, particularmente no que diz respeito à modalidade de voto antecipado ${ }^{35}$.

A mais dos aspectos enfatizados, e de muitos outros focos de incontrovertido interesse, foram alvo de permanente discussão, i.a.: (i) a falta de profissionais (e os modos de a suprir, com importação imediata, alargamento da rede de instituiçóes formadoras, relaxamento das constriçôes corporativas, etc.); (ii) os protocolos comunicacionais das autoridades; (iii) os programas e planos de testagem e, mais tarde, de vacinação; (iv) os sistemas de atendimento e monitorização à distância (por via telefónica); (v) a estratégia de articulação entre sectores económicos incluídos no sistema de saúde em sentido amplo; (vi) a eventual definição de regras de priorização ou racionamento no acesso aos cuidados; (vii) os apoios financeiros disponibilizados e as soluçóes de apoio económico-social às despesas empresariais com pessoal; ou (viii) a privacidade acossada pela rápida telematizaçáo e a iminência do recurso a sistemas de rastreamento electrónico de doentes. Pistas para um robustecimento da capacidade de resposta à emergência e adversidade - da população como um todo, das cidades, das regiôes e do pais, dos vários sectores económicos e sobremodo, do serviço nacional de saúde.

35 Da qual ficaram excluídos cidadãos sob vigilância depois de 14 de Janeiro e que geraram longas esperas, nem sempre nas condiçóes sanitariamente mais aconselháveis, nos dias aprazados para o efeito. 


\section{Elementos para uma Paideia ${ }^{36}$}

Do impacto causado pela pandemia na nossa auto-compreensão como habitantes de uma só Terra e membros de uma comum Humanidade, retirar-se-ão, decerto, muitas ilaçóes - desejavelmente interligadas, e profundas - quanto aos valores e direitos humanos, às constituiçóes e ao direito, às estruturas sociais que os garantem e instanciam e aos sujeitos, praxis e instituiçóes dessa estruturante responsabilidade.

Fica apenas um punhado de indícios, algo soltos, já que sistematicamente percutidos nas recomendaçóes mais adiante avançadas pelo grupo de trabalho responsável por todo o projecto.

- No relativo à saúde, propriamente dita: (i) a telemedicina e a saúde electrónica em rápido crescimento pedem um planeamento pensado, que não menoscabe a importância do contacto humano; (ii) há que revalorizar significativamente a saúde pública em todas as suas vertentes, tendo em conta a pirâmide dos impactos e os círculos de co-determinação da saúde; (iii) a resposta prestacional carece de integração a vários níveis (afinal, os hospitais continuam essenciais) e requer uma apropriação comunitária, pela qual os cidadáos participem responsavelmente da sua organização e funcionamento; (iv) depois de anos de desvario, ganham acuidade, pois, i.a., as agendas de comunização, integração, universalidade, interseccionalidade e transversalidade.

- De um ponto de vista científico-cultural e comunicativo-informacional, (i) a ciência tem de ser colaborativa e prestigiada, objecto de apoio e reconhecimento financeiro e social; (ii) o acesso à rede (internet) erigiu-se em direito fundamental, cuja provisão não pode ser deixada ao bel talante de operadoras só controladas por reguladores tíbios (concentrados na garantia de uma concorrência económica de resultados miríficos); (iii) as escolas e os estabelecimentos de saúde constituem zonas primárias de investimento, logo na qualidade de espaços comuns, abertos à sociedade e essenciais para garantir a manutenção segura das relaçôes sociais presenciais em momentos de crise; (iv) a criação e divulgação e os hábitos e media culturais desempenham um papel insubstituível

36 Num sentido não totalmente coincidente, v. Andrew Buchwalter, "Constitutional Paideia: Remarks on Hegel's Philosophy of Law”, PAIDEIA, World Congress of Philosophy (Political Philosophy), Boston, August, 1998. 
(inclusive no domínio da saúde mental e familiar) face ao deslaçamento social e ao vazio existencial;(vii) sobre os meios de comunicação recaem responsabilidades acrescidas durante crises como a que vivemos, seja em matéria de esclarecimento público, seja como garantes da crítica e da pluralidade de opinióes, ou mesmo no exercício de funçóes educativas e pedagógicas primaciais.

- No que à economia, em geral, diz respeito, (i) a crise não afecta todos igualmente, neste como noutros aspectos; (ii) fica patente a vantagem de uma coexistência entre os sectores económicos, vincando bem as suas diferenças para um relacionamento mais fecundo; (iii) o planeamento mostra-se crucial; (iv) a cooperação internacional pede melhoramentos urgentes; (v) as cadeias logísticas não podem escapar ao escrutínio e controlo das colectividades; (vi) desenvolvimento não se confunde, de facto, com crescimento;

- No plano urbano e habitacional, (i) tornou-se evidente a corporealidade humana e a consequente necessidade de luxo comum, enquanto aposta no que é de todos como lugar de qualidade, segurança, higiene, bem-estar e sociabilidade (por isso resistente à privatização e idiotizaçáo completa das existências); (ii) em paralelo, porém, a qualidade do parque habitacional continua a constituir um problema maior, assim como a (iii) articulação de um e outro, em modelos urbanos concebidos para o homem, na interface que garantem entre a vida privada e pública, particular e comunitária.

Chega-nos de algures a evocação das cidades em pandemia como surreais paisagens de De Chirico, abandonadas de homens. Nódulos fundamentais de um constitucionalismo em rede para um mundo citadino global, em expansáo imparável, elas redescobrem-se, porém, como lugar, por excelência, da reinventada (e)utopia - clássica e medieva, moderna e contemporânea - de realização e florescimento do homem. Havemos, pois, de nos empenhar na imaginação pública que as transforme, comprometidos a honrar as esperanças que para elas e nós fomos sonhando nestes tempos de dispersão isolada. Se assim for(mos dignos), como alguém também já sugeriu, ecoando o discurso nobel de Neruda, mais cedo do que tarde chegará o dia em que, enfim,

"A l'aurore, armés d'une ardente patience, nous entrerons aux splendides Villes."

(Rimbaud) 